\title{
Impactos do Processo de Aquisição na Estrutura, Estratégia e Cultura Organizacional: Estudo de Caso em uma Empresa do Mercado de Meios de Pagamento
}

\section{Impacts of the Process of Acquisition in the Structure, Strategy and Organizational Culture: Case Study in a Company of the Payment Market}

\author{
Geraldo Tessarini Juniora; Tiago Fonseca Albuquerque Cavalcanti Sigahia; Patrícia Saltorato ${ }^{\mathrm{a}}$
}

aUniversidade Federal de São Carlos, Programa de Pós-Graduação em Engenharia de Produção. SP, Brasil.

*E-mail:

\begin{abstract}
Resumo
Concebidas como operações para expandir e diversificar mercados, buscando aproveitar oportunidades de negócios, as Fusões e Aquisições (F\&A) são consideradas uma das mais recorrentes formas de reestruturação organizacional, cujos impactos atingem os mais variados aspectos, incluindo as decisões estratégicas, a estrutura organizacional e a cultura corporativa. Todos esses aspectos são essenciais para determinar o sucesso ou o fraco de um processo de F\&A e não podem ser negligenciados. Sob essa perspectiva, o presente artigo tem como objetivo explorar o processo de aquisição de uma empresa do mercado de pagamentos brasileiro, investigando as principais mudanças e impactos na estratégia e na estrutura organizacional e a percepção e adaptação dos funcionários aos novos elementos culturais desta empresa decorrentes de tal processo. A pesquisa foi conduzida tendo como base, fontes documentais tais quais relatórios e apresentações internas da empresa e; entrevistas com executivos dos níveis operacional, tático e estratégico, que vivenciaram o processo de aquisição tanto na empresa adquirida quanto na adquirente. Os resultados evidenciaram que elementos culturais da instituição financeira adquirente foram rapidamente incorporados à empresa estudada. A estratégia e a estrutura organizacional da empresa sofreram alterações em sua forma de solucionar problemas gerenciais, melhorar indicadores estratégicos de desempenho e aumentar a sinergia entre as duas empresas.
\end{abstract}

Palavras-chave: Estratégia. Estrutura Organizacional. Mercado de Pagamentos. Fusões e Aquisições.

\begin{abstract}
Planned as operations to expand and diversify markets, in order to take advantage of business opportunities, mergers and acquisitions (M\& A) are considered one of the most recurrent forms of organizational changes, whose impacts affect the most varied aspects, including strategic decisions, organizational structure and corporate culture. All these aspects are essential to determine the success or weakness of a M\&A process and can not be neglected. In this perspective, this article aims to explore the process of acquiring in a company from the Brazilian payments market, investigating the main changes and impacts in the strategy and organizational structure and the perception and adaptation of the employees to the new cultural elements resulting from such process. The research was carriet out through documentary sources, such as internal reports and presentations, and interviews with executives at the operational, tactical and strategic levels who experienced the acquisition process both in the acquired company and in the acquirer. The results showed that acquirer's cultural elements were quickly incorporated into the acquired company. The strategy and organizational structure of the acquired company undergone changes as a way to solve managerial problems, improve strategic performance indicators and increase the synergy between the two firms.
\end{abstract}

Keywords: Strategy. Organizational Structure. Payment Market. Mergers and Acquisitions.

\section{Introdução}

O cartão de crédito/débito representou um grande avanço no mercado de meios de pagamento em termos de segurança e praticidade. A aceitação dessa forma de pagamento foi tamanha que, em 2013, segundo a Associação Brasileira de Cartões de Crédito e Serviços (ABECS, 2013), enquanto as transações utilizando cartões já representavam 54\% do faturamento mensal dos estabelecimentos comerciais brasileiros, aquelas mais tradicionais, envolvendo dinheiro e cheque, representavam $35 \%$ e $4 \%$, respectivamente.

Aliado a esse crescimento expressivo, o mercado financeiro brasileiro e, em especial, o mercado de meios de pagamento tem passado por constantes transformações impulsionadas tanto por fatores externos (e.g. expansão de conglomerados financeiros em escala global), quanto internos (e.g. regulamentação de mercados). Esse contexto provocou e continua provocando mudanças nas diretrizes estratégicas das instituições, inclusive com o desencadeamento de uma onda de fusões e aquisições (F\&A). Estas, por sua vez, têm se provado uma intervenção positiva nas métricas de rentabilidade das instituições adquirentes e uma estratégia ante à concorrência e à necessidade de sobrevivência em mercados globais, dinâmicos e incertos (PESSANHA et al., 2012; MEDEIROS; LOPES; POSSAS, 2013), sendo realizadas, principalmente, por organizações maiores, mais líquidas, mais eficientes e com maiores históricos de crescimento (PIMENTA; GARNER, 2014).

Concebidas, portanto, como parte de uma ampla estratégia para proporcionar resultados mais expressivos às empresas envolvidas, com vistas a expandir e diversificar mercados ou aproveitar oportunidades de negócios (BERGMANN et al., 2015; CAMARGOS; CAMARGOS, 2015), as operações de 
F\&A compreendem um complexo conjunto de decisões que provoca impactos diretos nos mais diversos stakeholders, entre os quais funcionários, acionistas, concorrentes, fornecedores e clientes (CAMARGOS; CAMARGOS, 2015; FILIPOVIĆ; PODRUG; KANDŽIJA, 2017).

Tais operações podem ser analisadas a partir das mais diversas perspectivas. Entretanto, a literatura acadêmica tem privilegiado aspectos relacionados aos motivos e às hipóteses que justificam sua realização (BERNARDO; CAMPOS FILHO, 2011; FILIPOVIĆ; PODRUG; KANDŽIJA, 2017) e o sucesso ou fracasso decorrentes do processo, sobretudo pelo aspecto econômico-financeiro e de criação de valor aos acionistas (CAMARGOS; CAMARGOS, 2015). Verificase pouca ênfase a outras variáveis importantes presentes em processos de F\&A e que afetam diretamente o desempenho organizacional, entre elas a estratégia, a estrutura e a cultura organizacional (FILIPOVIĆ; PODRUG; KANDŽIJA, 2017).

A necessidade dessa compreensão se relaciona ao fato de que a cultura organizacional é um fenômeno "multifacetado, difícil de interpretar e formado por conflitos, dissensos, diversidades, e por elementos de integração" (MEDEIROS; LOPES; POSSAS, 2013, p. 560), portanto, a consecução de um processo de F\&A provocará um inevitável choque cultural (REGO, 2014), que representa um desafio aos gestores e um aspecto essencial na almejada integração entre as empresas (PARDINI; MACHADO; OLIVEIRA, 2017).

É nesse cenário de mudanças, incertezas e riscos que a cultura organizacional é "testada" durante uma F\&A (SILVA; DUARTE, 2012). Apesar da flexibilidade cada vez maior das culturas organizacionais, transformá-las é um processo árduo e de grande complexidade, o qual exige mudanças nas relações interpessoais e nos procedimentos, além da implementação de novos sistemas de controle (HOFSTEDE, 2010). É necessário, ainda, estabelecer que a cultura organizacional possui estreita relação com a estratégia e com a estrutura adotadas por uma organização, sendo, ao mesmo tempo, uma variável preditiva e dependente de ambas. Freitas (1991) observou que, a depender da abordagem, a cultura pode aparecer como um subsistema ligado à estrutura, à estratégia, aos sistemas políticos e técnicos, ou como uma superestrutura que determina todas as outras.

Dessa maneira, é natural que, além dos impactos na cultura organizacional, as mudanças provocadas por uma F\&A afetarão também as decisões estratégicas da organização, podendo acarretar, inclusive, em mudanças em sua estrutura. É comum que para melhor adequação às novas estratégias e às mudanças ambientais e organizacionais, sejam necessárias adaptações na estrutura organizacional (TORTATO; DEL CORSO, 2008; DAVID 2002), a qual, por sua vez, representa o primeiro contato direto dos trabalhadores com a estratégia da empresa, revelando a importância da sinergia entre elas (MINTZBERG; AHLSTRAND; LAMPEL, 2010). Ocorre, conforme Chandler (1962), o condicionamento e influência mútuos entre estrutura e estratégia organizacional. A estrutura deve ser estabelecida de maneira a facilitar o alcance dos objetivos da empresa e o seu alinhamento à estratégia decorre, principalmente, por representar a forma como os diversos recursos físicos, financeiros, materiais e humanos da empresa são alocados (DAVID, 2002).

Feitas essas considerações, entende-se ser necessário, assim como ressaltam Medeiros, Lopes e Possas (2013), a efetivação de estudos sob uma ampla perspectiva organizacional integrando aspectos estratégicos (os objetivos, a estrutura) aos culturais (as pessoas, as mudanças, as reações envolvidas). Isso porque, embora as F\&A sejam predominantemente efetivadas sob um discurso idealista de construção de um futuro promissor, as mudanças por elas provocadas são permeadas por aspectos subjetivos e possivelmente nocivos aos trabalhadores, como perda de identidade, desgaste emocional, ansiedade, estresse, medo, angustia e uma falsa percepção de que todas as adversidades serão resolvidas com o tempo (CALDAS; TONELLI, 2002). Todos esses aspectos tornam as F\&A uma das mais dramáticas formas de mudança organizacional (REGO, 2014).

Nesse sentido, surgem algumas questões inspiradoras: como os processos de F\&A impactam nas decisões estratégicas da organização? Qual a influência desse processo sobre a estrutura organizacional das empresas envolvidas? E sobre os funcionários? Como estes se defrontam e se relacionam com os novos elementos culturais invariavelmente transportados de uma empresa para outra? Há resistência ou adaptação?

Nesta pesquisa, procura-se analisar tais questões pelo ponto de vista da empresa adquirida. Busca-se, como objetivo principal, explorar o processo de aquisição de uma empresa do mercado de pagamentos brasileiro, investigando as principais mudanças e impactos na estratégia e na estrutura organizacional e a percepção e a adaptação dos funcionários aos novos elementos culturais desta empresa decorrentes de tal processo.

\section{Material e Métodos}

Esta pesquisa pode ser caracterizada como um estudo de caso de abordagens descritiva e qualitativa, realizado junto a uma grande empresa do mercado de soluções de pagamentos, a qual, para fins de anonimato, será denominada como Credenciadora 1. A empresa em análise foi recentemente adquirida por uma grande instituição financeira, denominada como Banco 1, o que levou a mudanças estratégicas em sua gestão, tanto para adequação à nova realidade do mercado, quanto por influência da instituição que a adquiriu.

Para efetivação do estudo foram combinadas duas estratégias metodológicas: pesquisa documental e entrevistas. A pesquisa documental foi utilizada como mecanismo para obtenção de informações sobre o mercado no qual a empresa está inserida e de dados internos, como a sua estrutura organizacional, faturamento e market share. Foram 
consultados relatórios econômicos, matérias veiculadas na imprensa de negócios, apresentações internas, relatórios de demonstrações financeiras, apresentações para investidores e estudos setoriais nacionais realizados pela ABECS.

O propósito das entrevistas foi coletar informações de cunho subjetivo em relação à empresa, como a formalidade das interações, o relacionamento dos funcionários com os gestores, os valores e as políticas adotadas, a percepção dos funcionários quanto às estratégias e cultura organizacional, entre outros. Buscou-se compreender a situação da
Credenciadora 1 antes e depois da sua aquisição, ou seja, os impactos desse processo em termos de estratégia, cultura e estrutura organizacional. Com isso, foi possível analisar, do ponto de vista dos funcionários, como as mudanças advindas da aquisição afetaram o dia a dia da empresa.

Foram realizadas nove entrevistas não estruturadas com executivos dos níveis operacional, tático e estratégico de diferentes áreas e cargos, que vivenciaram o processo de aquisição tanto na empresa adquirida quanto na adquirente, conforme o Quadro 1:

Quadro 1 - Caracterização dos entrevistados

\begin{tabular}{|c|c|c|c|c|c|}
\hline Identificação & Cargo/Área & Empresa Atual & $\begin{array}{l}\text { Empresa } \\
\text { Período } \\
\text { Aquisição } \\
\end{array}$ & $\begin{array}{c}\text { Duração da } \\
\text { Entrevista }\end{array}$ & Motivo da Entrevista \\
\hline Analista-Plan1 & $\begin{array}{l}\text { Analista de } \\
\text { planejamento } \\
\text { comercial e } \\
\text { franquias }\end{array}$ & Credenciadora 1 & Credenciadora 1 & $2,5 \mathrm{~h}$ & $\begin{array}{l}\text { Acompanhou o processo de aquisição } \\
\text { e possui conhecimento sobre a empresa } \\
\text { por atuar na função há oito anos }\end{array}$ \\
\hline Analista-Plan2 & $\begin{array}{l}\text { Analista de } \\
\text { planejamento } \\
\text { comercial e } \\
\text { franquias }\end{array}$ & Credenciadora 1 & Banco 7 & $1 \mathrm{~h}$ & $\begin{array}{l}\text { Acompanhou três processos de fusão } \\
\text { e aquisição entre empresas do setor } \\
\text { financeiro brasileiro }\end{array}$ \\
\hline $\begin{array}{l}\text { Analista- } \\
\text { Telemetria }\end{array}$ & $\begin{array}{l}\text { Analista de } \\
\text { telemetria }\end{array}$ & Banco 1 & Credenciadora 1 & 20 min. & Atuou na Credenciadora 1 e no Banco 1 \\
\hline $\begin{array}{c}\text { Analista- } \\
\text { Parceria }\end{array}$ & $\begin{array}{c}\text { Analista de } \\
\text { parcerias }\end{array}$ & Credenciadora 1 & Credenciadora 1 & $1,5 \mathrm{~h}$ & $\begin{array}{l}\text { Acompanhou o processo de aquisição } \\
\text { e possui conhecimento sobre a empresa } \\
\text { por atuar na função há nove anos }\end{array}$ \\
\hline Coord-Plan & $\begin{array}{l}\text { Coord. de } \\
\text { planejamento } \\
\text { comercial e } \\
\text { franquias }\end{array}$ & Credenciadora 1 & Banco 1 & $35 \mathrm{~min}$. & Atuou no Banco 1 e na Credenciadora 1 \\
\hline $\begin{array}{l}\text { Gerente- } \\
\text { Comercial }\end{array}$ & $\begin{array}{c}\text { Gerente } \\
\text { comercial } \\
\text { (Segmento 7) }\end{array}$ & Credenciadora 1 & Credenciadora 1 & $30 \mathrm{~min}$. & $\begin{array}{l}\text { Acompanhou o processo de aquisição } \\
\text { e possui conhecimento sobre a empresa } \\
\text { por atuar na função há nove anos }\end{array}$ \\
\hline Gerente-Incent & $\begin{array}{l}\text { Gerente de } \\
\text { incentivos }\end{array}$ & Credenciadora 1 & Banco 7 & $3 \mathrm{~h}$ & $\begin{array}{l}\text { Atua no nível tático como responsável } \\
\text { pela distribuição das metas comerciais, } \\
\text { possui amplo conhecimento sobre os } \\
\text { processos de gestão e comunicação } \\
\text { interna }\end{array}$ \\
\hline Superint-Plan & $\begin{array}{l}\text { Superintendente } \\
\text { de planejamento } \\
\text { comercial e } \\
\text { franquias }\end{array}$ & Credenciadora 1 & Banco 1 & $1 \mathrm{~h}$ & $\begin{array}{l}\text { Atua no nível estratégico como } \\
\text { superintendente e possui amplo } \\
\text { conhecimento sobre o processo de } \\
\text { implementação do modelo de franquias } \\
\text { na Credenciadora } 1\end{array}$ \\
\hline Superint-Parc & $\begin{array}{l}\text { Superintendente } \\
\text { de parcerias e } \\
\text { incentivos }\end{array}$ & Credenciadora 1 & Banco 1 & $45 \mathrm{~min}$. & $\begin{array}{l}\text { Atua no nível estratégico como } \\
\text { superintendente e possui amplo } \\
\text { conhecimento sobre os mecanismos } \\
\text { de atribuição de metas tanto na } \\
\text { Credenciadora } 1 \text { quanto no Banco } 1 \\
\end{array}$ \\
\hline
\end{tabular}

Fonte: Dados da pesquisa.

Como cada um dos entrevistados foi selecionado por um motivo específico, a estratégia foi explorar determinada qualidade/característica do participante conduzindo a entrevista de forma que o tema fosse abordado livremente, inclusive com o relato de casos e vivências, assim como outros assuntos correlatos ao objetivo da pesquisa. Tais entrevistas foram realizadas entre novembro/2017 e agosto/2018 em diferentes ambientes, dentro e fora da empresa, dependendo das necessidades e escolhas dos entrevistados.

\section{Resultados e Discussão}

Os resultados obtidos pela triangulação das estratégias metodológicas são apresentados e discutidos a partir de subseções que descrevem todo o processo de aquisição da Credenciadora 1, bem como seus impactos. Ao longo do texto, são inseridas falas dos entrevistados que corroboram e transcrevem, com maiores detalhes, a trajetória experimentada pela empresa. 


\subsection{Caracterização histórica da empresa e do mercado}

No início da década de 70 , três bancos se reuniram para transformar uma bandeira criada alguns anos antes como cartão vinculado à área de turismo em uma instituição financeira capaz de desempenhar as funções de bandeira, emissor e credenciadora. Assim, criou-se a Empresa 1, concentrando em uma única organização toda a renda proveniente de uma transação utilizando o cartão. A nova organização teve sucesso, chegando até mesmo a alcançar a liderança do mercado.

Em 1983, a empresa constatou que apenas ter sua própria bandeira poderia limitar sua expansão, visto que grandes bandeiras mundiais já haviam chegado ao Brasil. Nesse ano, foi feita uma parceria com a Visa - bandeira líder nacional em número de cartões. Contudo, em 1987, a empresa decidiu guinar à concorrência, efetuando uma associação de exclusividade na captura das transações dos cartões da bandeira MasterCard. Foi nesse mesmo ano que a empresa lançou o primeiro cartão de débito do mercado brasileiro.

Devido ao forte crescimento das operações, em 1996, os três bancos que administravam a Empresa 1 observaram a necessidade de especialização dos serviços prestados. Decidiram, então, desmembrar as operações de credenciamento e, nesse momento, nasceu a Credenciadora 1 - objeto central desta pesquisa. Apesar de lançada como uma empresa independente, a empresa guardava fortes relações com o grupo a qual fazia parte.

Paralelamente ao acordo de exclusividade feito entre a MasterCard e a Empresa 1, outro acordo de exclusividade foi feito entre a bandeira Visa e outra adquirente, a Credenciadora 2, que, por sua vez, também possuía parceria com outros 3 grandes bancos - dois estatais e um privado. A Figura 1 apresenta a configuração do mercado de pagamentos em 1996, ano em que a Empresa 1 desmembrou as operações de crédito, dando vida à Credenciadora 1. O mercado, até então, estava dividido em dois grandes grupos, formados por bancos, credenciadoras e bandeiras. Os bancos, acionistas das credenciadoras, possuíam preferência pela emissão de cartões da bandeira parceira e, com isso, inflaram o mercado com cartões que só eram aceitos em terminais eletrônicos da credenciadora também parceira.

Figura 1 - Configuração do mercado de pagamentos nacional em 1996

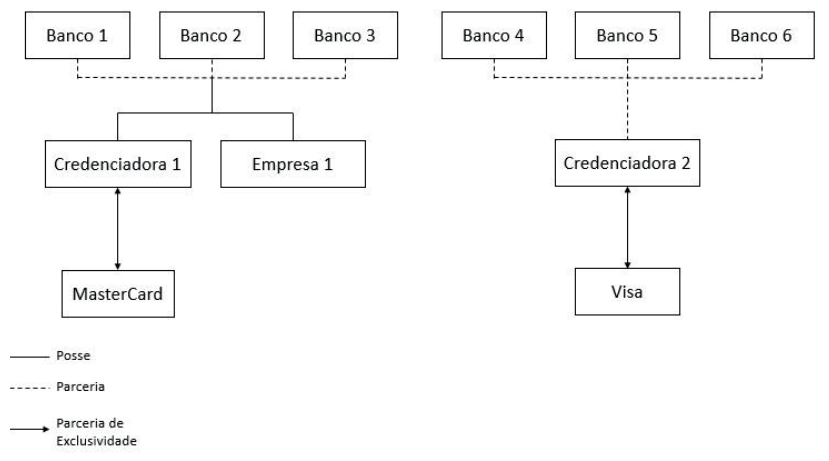

Fonte: Os autores.

\subsection{Regulamentação do mercado}

O mercado de pagamentos se manteve dessa forma durante muito tempo e se desenhava ainda mais favorável às Credenciadoras 1 e 2 pelo fato de que, em 2010, segundo dados do Banco Central do Brasil (BACEN, 2011), a Visa possuía uma fatia de $52,2 \%$ do mercado em volume de transações, enquanto a MasterCard possuía 38,4\%.

Esse cenário praticamente obrigava todos os estabelecimentos comerciais a possuírem terminais eletrônicos da Credenciadora 1 e da Credenciadora 2, sob o risco de perderem vendas ao não conseguir receber pagamentos de clientes que possuíam cartão de alguma das duas bandeiras que dominavam o mercado. Além disso, era muito difícil que outra empresa conseguisse entrar no mercado, visto que, com a exclusividade das Credenciadoras 1 e 2 sobre as transações das duas maiores bandeiras em número de cartões, a rentabilidade certamente seria muito baixa.

Em 2010, o BACEN, em conjunto com a Secretaria de Acompanhamento Econômico (SEAE), lançou um relatório explicitando a necessidade de regulamentação do mercado de pagamentos devido ao duopólio existente (as credenciadoras 1 e 2 possuíam juntas mais de $90 \%$ do mercado). A regulamentação, conhecida como abertura de mercado, quebrou a exclusividade da Credenciadora 1 com a MasterCard e da Credenciadora 2 com a Visa, permitindo que qualquer adquirente pudesse captar transações das duas bandeiras.

Para os lojistas, a abertura de mercado significou a possibilidade de negociar as taxas cobradas por transação e o preço do aluguel, permitindo atender a demanda de transações das duas maiores bandeiras utilizando apenas um único terminal. Já para as Credenciadoras 1 e 2, representou o fim de um período de comodidade e o início de uma intensa competição por market share, uma vez que também facilitava a entrada de novos players no mercado.

Para o Analista-Plan1, que na época já trabalhava na Credenciadora 1, o período da regulamentação foi especialmente complicado para a empresa. Segundo ele, apesar do Banco 1, que detinha 50\% das ações da Credenciadora 1 , exercer pouca influência na tomada de decisões da empresa, havia um certo consenso entre o Banco 1 e a Credenciadora 1 de priorizar a busca por "clientes grandes", ou seja, com maior potencial de faturamento

Enquanto isso, a Credenciadora 2 conseguiu ampliar seu market share, aumentando sua vantagem em relação à Credenciadora 1, sobretudo no varejo. Diante do novo cenário, a Credenciadora 1 resolveu, entre o final de 2011 e o início de 2012, mudar sua estratégia e focar mais na captação e retenção de clientes com baixo potencial de faturamento, mas que em larga escala acabavam sendo mais rentáveis. Contudo, em 2012, ocorreu outra mudança que transformaria drasticamente os rumos da empresa. 


\subsection{A aquisição da credenciadora 1}

Desde sua criação, o capital da Credenciadora 1 era dividido igualmente entre os Bancos 1, 2 e 3. Em 2007, ano em que teve seu capital aberto na antiga Bolsa de Valores de São Paulo (BOVESPA), cada um dos bancos reduziu sua participação em uma operação que movimentou $\mathrm{R}$ 4,07 bilhões. Posteriormente, o Banco 3 vendeu o restante das suas ações.

Em 2010, em uma das mais famosas operações do mercado financeiro brasileiro, os Bancos 1 e 2 concretizaram sua fusão, formando o maior banco do hemisfério sul. Nesse momento, o Banco 1 passou também a ter controle sobre as ações que o Banco 2 possuía da Credenciadora 1, tornando-se acionista majoritário. No início de 2012, o Banco 1 lançou uma Oferta Pública de Aquisição (OPA), declarando seu interesse em fechar o capital da Credenciadora 1. A operação foi finalizada em outubro de 2012, quando o Banco 1 incorporou a Credenciadora 1 ao seu conglomerado após desembolsar R\$ 11,3 bilhões.

Para o Coord-Plan, a ação do Banco 1 de adquirir a Credenciadora 1 foi condizente a sua estratégia. Segundo ele, o Banco 1, historicamente, não é uma empresa que cresce de forma natural; seu crescimento sempre ocorreu através de aquisições. Além disso, foi uma excelente oportunidade de estar presente em todo o processo de pagamento digital: mais uma vez o Banco 1 buscava reunir as funções de credenciadora, bandeira e emissor.

Entretanto, para o Gerente-Incent, o principal motivo que levou o banco a investir na aquisição da Credenciadora 1 foi sua estratégia de aumentar a participação de receitas que não advém do crédito. Isso porque, apesar dos produtos que envolvem crédito possuírem grande rentabilidade, eles possuem alto risco. A Credenciadora 1 se encaixava em um modelo de negócio com alta rentabilidade e baixo risco, bastante adequado ao que o banco desejava.

No período entre o lançamento da OPA e a concretização da aquisição, as primeiras mudanças causadas pela influência do Banco 1 na gestão da Credenciadora 1 começaram a ser percebidas. De acordo com o Analista-Plan1, por influência do Banco 1, a Credenciadora 1 reduziu as operações de credenciamento via empresas terceirizadas e eliminou algumas centrais de telemarketing, restringindo bastante sua força de venda. Segundo o entrevistado:

Alguns executivos foram demitidos via mensagem de texto [...] esse período ficou conhecido entre alguns funcionários como um período de devastação da empresa.

Todavia, o problema era ainda maior porque, como relatado pelo Analista-Plan1 e pelo Gerente-Comercial, tanto a força de venda terceirizada quanto as operações de telemarketing eram mais voltadas ao credenciamento e ao atendimento de clientes de menor potencial de faturamento. Para o AnalistaParceria, foi a primeira vez que o Banco 1 promoveu uma ação com grande impacto na estratégia da Credenciadora 1:
Foi o primeiro grande choque entre a estratégia que vinha sendo implementada na Credenciadora 1 e a estratégia que o Banco 1 iria implementar na empresa dali para frente.

\subsection{Impactos na cultura organizacional}

Para o Analista-Plan2, que já passou por três processos de F\&A, é normal que a cultura e a estratégia da empresa compradora se sobressaiam em relação à empresa adquirida. De fato, segundo os entrevistados que participaram do processo, foi o que ocorreu. As principais mudanças culturais percebidas pelos funcionários foram:

- Meritocracia: um dos pilares da cultura do banco, foi rapidamente incorporada à cultura da Credenciadora 1 ;

- Competitividade: a cultura meritocrática estimula a competitividade entre os funcionários, algo que hoje está enraizado também na cultura da Credenciadora 1;

- Funcionários: a Credenciadora 1 tem buscado funcionários e líderes mais jovens. O perfil exigido é o de trabalhadores focados na inovação e aderentes à cultura de meritocracia e competitividade;

- Hierarquia: com a chegada do Banco 1, a hierarquia ficou mais vertical, reduzindo o contato entre pessoas de cargos mais baixos com a alta gerência da empresa;

- Governança: o Banco possui processos mais regulamentados e, consequentemente, mais lentos;

- Formalidade: a cultura do banco preza por uma formalidade maior, tanto na vestimenta, quanto na maneira de lidar com funcionários e clientes;

- Gastos: grande foco em redução de custos;

- Perenidade das ações: a Credenciadora 1 enfatizava ações de curto prazo e, após a aquisição pelo Banco 1, o foco passou a ser em ações mais perenes;

- Digitalização: uma das marcas do banco e que passou a ser também da Credenciadora.

As mudanças na alta gerência da Credenciadora 1 foram profundas, inclusive com a troca do presidente da empresa. Alocar funcionários do banco em cargos de liderança na Credenciadora 1 foi, para o Analista-Parceria, uma estratégia utilizada que realmente acelerou o processo de assimilação da cultura do Banco 1. Para ela, o estilo de gestão era diferente e, na adaptação ao novo modelo, era normal que o comportamento fosse se moldando à nova realidade. Apesar disso, de acordo com o Superint-Plan, inicialmente houve rejeição dos funcionários da Credenciadora 1 a alguns elementos culturais do Banco 1:

Lembro que quando cheguei do banco para a credenciadora para um cargo de liderança, as pessoas que já estavam na área me receberam com certo receio. Eles tinham medo de que eu fosse implementar uma cultura de competitividade e que isso prejudicaria o clima de amizade que já existia lá.

Outro complexo elemento foi o estabelecimento de maior governança nos processos da empresa. Para o Analista-Plan1, os processos se tornaram muito lentos e engessados em um mercado que exige respostas rápidas. $\mathrm{O}$ Analista-Telemetria, por sua vez, afirma que os processos anteriores realmente eram mais simples e ágeis, porém mais ineficazes, gerando retrabalho. O Gerente-Incent, que concorda com o ponto de 
vista do Analista-Telemetria, inclusive conecta a governança implementada com a busca por ações mais perenes.

Após a aquisição, a Credenciadora 1 teve grande aumento em sua capacidade de investimentos. Para o Gerente-Comercial e o Analista-Telemetria, isso também foi fundamental para que algumas características da cultura do Banco 1 fossem rapidamente incorporadas ao dia a dia da empresa, como o foco em digitalização e inovação tecnológica - uma das estratégias competitivas do Banco 1 que também se tornaram da Credenciadora 1.

Mudanças nas formas de avaliação de desempenho dos funcionários foi outra estratégia utilizada para garantir a sintonia dos trabalhadores à nova cultura. Seguindo os ideais de meritocracia existentes no Banco 1, o modelo implementado na credenciadora aproximou-se ao modelo já utilizado no banco. Tal modelo é baseado em uma avaliação quantitativa, com notas variando entre 1 e 5 para dois parâmetros diferentes. $\mathrm{O}$ primeiro refere-se à quantidade, qualidade, tamanho e impacto dos projetos e atividades realizadas. O segundo avalia a aderência dos trabalhadores aos valores da empresa, de acordo com suas atitudes cotidianas, compreendendo aspectos avaliativos essencialmente subjetivos, como o comportamento ético do funcionário, o respeito a diferentes opiniões, a contribuição para um bom clima organizacional e proatividade. A partir dessas notas, os trabalhadores são divididos em cinco diferentes grupos (Figura 2).

Figura 2 - Representação do modelo de avaliação

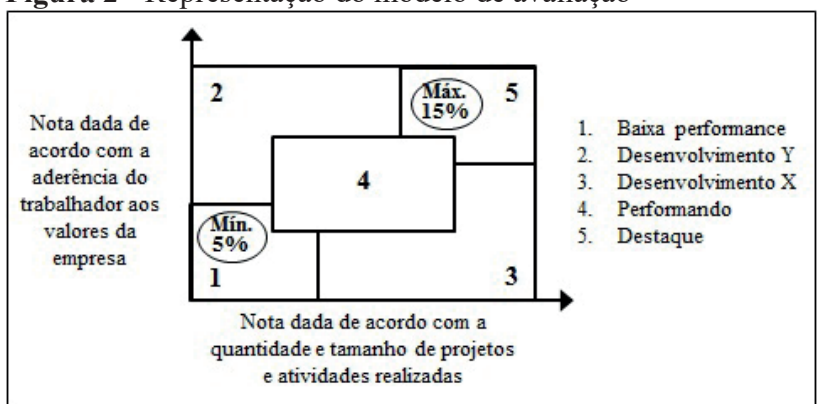

Fonte: Os autores.

O grupo 1, de pior performance, deve conter no mínimo $5 \%$ dos funcionários, enquanto o grupo 5 , de melhor avaliação, deve conter no máximo $15 \%$ do total. Essa avaliação é um fator determinante para demissões, aumentos salariais, promoções na carreira e outras formas de reconhecimento.

No início de 2015, segundo o Superint-Parc, a credenciadora já havia assimilado os principais pontos da cultura organizacional do banco. Mas, os resultados obtidos, considerados abaixo do esperado, evidenciaram a necessidade de maior integração entre os negócios das empresas. Ainda nesse ano, como tentativa de solução, boa parte do contingente de trabalhadores da Credenciadora 1 foi transferido da sua sede para a sede do Banco 1.

\subsection{Mudanças na estratégia e na estrutura organizacional}

Apesar da queda nos resultados da Credenciadora 1, o seu rendimento e o baixo risco da sua operação, em um contexto de crise econômica e recessão de crédito, levaram o Banco 1 a concentrar ainda mais suas atenções no mercado de meios de pagamentos. Os resultados da Credenciadora 1 mostravam que seu RGO (Resultado Geral Operacional) tinha grande representatividade dentro do resultado do banco, principalmente nos segmentos com clientes de menor faturamento.

O ano de 2016 foi marcado por mudanças de grande impacto que buscaram aumentar a sinergia entre as empresas, destacando-se a nova segmentação comercial, a equiparação das metas comerciais, a implementação do modelo de franquias e as mudanças na estrutura organizacional.

Quanto à segmentação comercial, a estrutura da Credenciadora 1 era segmentada de acordo com a faixa de faturamento dos clientes (Figura 3). Cada segmento contava com gerentes e coordenadores, e abaixo destes últimos estavam os promotores terceirizados (segmento 5) ou executivos contratados (demais segmentos).

Figura 3 - Estrutura comercial da Credenciadora 1 antes das mudanças estratégicas

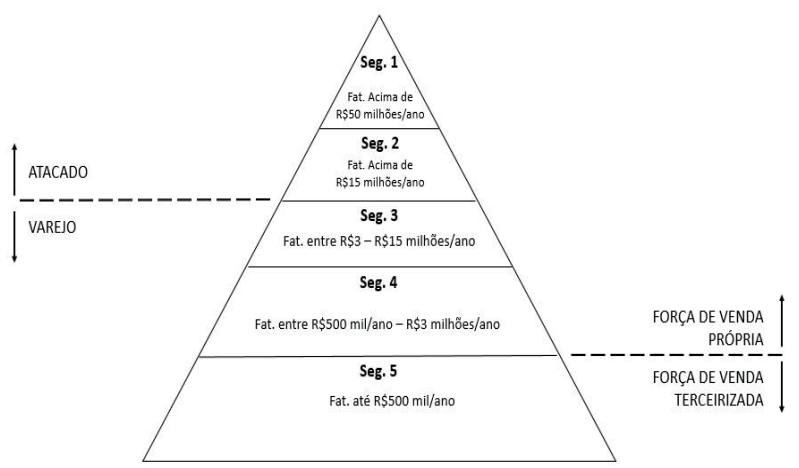

Fonte: Os autores.

A nova segmentação comercial (Figura 4) foi elaborada com o intuito de proporcionar uma forma mais assertiva de banco e credenciadora trabalharem em conjunto com os clientes. A principal mudança foi a separação dos clientes em correntistas e não correntistas, ou seja, entre os que possuem ou não conta no banco. A separação possibilitou analisar e criar ações específicas para cada um dos clientes. Por exemplo, no caso de um cliente correntista, é possível saber quanto do seu faturamento total passa pelo terminal da Credenciadora 1. Caso ele tenha grande parte do seu faturamento sendo processado por outras credenciadoras, é comum a oferta de taxas mais baratas buscando converter um percentual maior do faturamento para a Credenciadora 1. Ao mesmo tempo, para os clientes que não são correntistas, é possível oferecer descontos em caso de troca de seu domicílio bancário para o Banco 1. 
Figura 4 - Estrutura comercial da Credenciadora 1 após as mudanças estratégicas

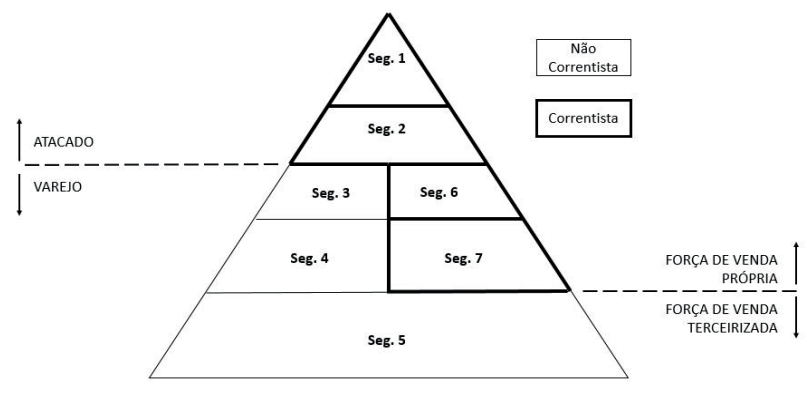

Fonte: Os autores.

Outra mudança de grande impacto foi a equiparação das metas comerciais. Tanto no Banco 1 quanto na Credenciadora 1 a remuneração variável representa uma parcela significativa do salário recebido pelos membros da área comercial. O ganho é diretamente proporcional à produtividade e ao alcance das metas previamente definidas, cujo processo de definição é complexo e leva em consideração diversos aspectos, como o local de atuação e o perfil dos clientes atendidos.

Antes da equiparação, a Credenciadora 1 possuía grande foco em quantitativo de vendas e, com isso, trabalhava com "indicadores táticos", que são aqueles que visam medir o desempenho do funcionário em relação a vendas e aos novos clientes credenciados. Atualmente, o modelo trabalha com "indicadores de carteira", que medem a eficiência com que a carteira de clientes é trabalhada. Faturamento e receita são exemplos desse tipo de indicador. Dessa forma, muda-se o foco do quantitativo de clientes para a qualidade com que se lida com eles, sobretudo no que diz respeito à sua capacidade de trazer receita. Essa mudança permitiu com que a remuneração variável dos trabalhadores estivesse condizente às estratégias e aos resultados obtidos pela empresa.

Um dos maiores problemas enfrentados pela Credenciadora 1 apontado pelos entrevistados era a comunicação ineficiente entre a área comercial e as demais áreas da empresa. Isso acarretava em inúmeros problemas, entre eles:

- Venda de produtos inacabados ou pouco testados;

- Vendas de terminais em locais onde a área de logística não atendia;

- Lançamento de produtos sem estudos de rentabilidade e/ ou previsão de vendas;

- Dificuldade de padronização na atuação da área comercial;

- Ausência de treinamentos para os trabalhadores da área comercial sobre os produtos que estavam vendendo;

- Baixo alinhamento entre os produtos ofertados e as necessidades dos clientes.

Sobre este último, o Gerente-Incent é taxativo ao afirmar:

Como o resultado obtido pelo produto entrava na meta da área que o elaborou, eles tentavam forçar a barra para que fosse vendido. Com isso, muitas vezes eram oferecidos aos clientes uma série de produtos que eles não tinham a menor necessidade, reduzindo muito a assertividade das vendas.
Como tentativa de minimizar esses problemas, decidiuse pela implementação de um modelo de franquias, o qual já existia com sucesso no Banco 1. Os objetivos fundamentais eram oferecer o "produto certo ao cliente certo", aumentar a performance comercial e a governança dos processos internos. Com isso, as gerências de planejamento comercial foram transformadas em gerências de franquias e planejamento. Assim, cada gerência de planejamento ganhou ao menos uma coordenação de franquias responsável por intermediar a comunicação entre a área comercial e as demais.

Além disso, a área de franquias ficou responsável por difundir as melhores práticas de gestão de vendas para toda a área comercial, através de modelos de atuação e treinamentos. Os modelos de atuação, por exemplo, contêm informações sobre atividades diárias, semanais e mensais que devem ser executadas, explicam a importância do alinhamento estratégico da equipe com a empresa, definem as responsabilidades de cada cargo e também se configuram como uma espécie de manual de atuação em diferentes situações de vendas. O objetivo é a padronização da atuação comercial, buscando maior efetividade nas abordagens e o aumento no número e na qualidade das vendas. Conforme relatou o Superint-Plan:

Antes da existência das franquias, quando um executivo era contratado para a área comercial, o treinamento era passar alguns dias acompanhando algum outro executivo que tinha bons resultados. O problema é que ninguém sabia os reais motivos para aquele executivo ter bons resultados. Ele podia, por exemplo, estar fraudando vendas, o que acontece bastante nesse negócio.

A implementação do modelo de franquias também representou a primeira mudança na estrutura organizacional da Credenciadora 1, com o objetivo de descentralizar as decisões estratégicas da área comercial e dar maior poder às áreas de planejamento, agora apoiadas pelo modelo de franquias. Enquanto, a Figura 5 apresenta o organograma da empresa antes do processo de aquisição, a Figura 6 o apresenta após a implementação do modelo de franquias.

Figura 5 - Organograma da Credenciadora 1 antes do processo de aquisição

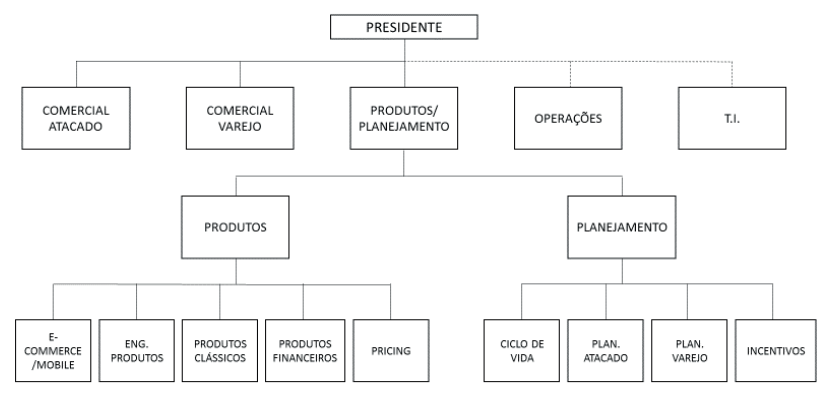

Fonte: Os autores. 
Figura 6 - Organograma da Credenciadora 1 após implementação do modelo de franquias

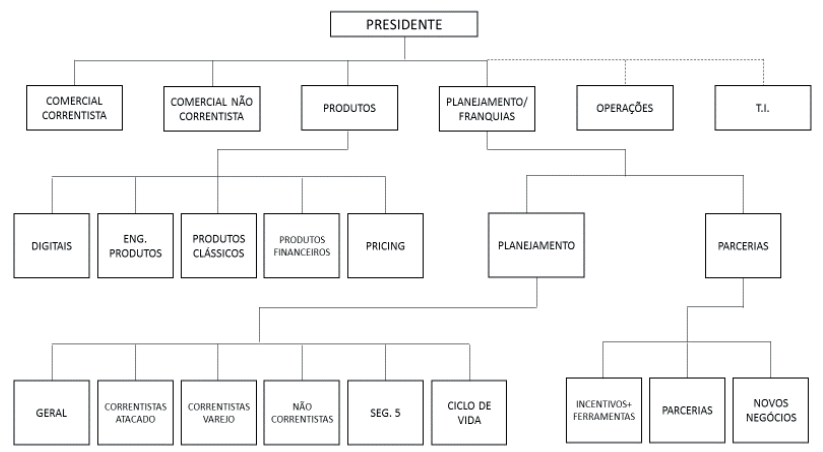

Fonte: Os autores.

Durante o processo de mudanças foi possível perceber uma grande alteração nas diretrizes comerciais da Credenciadora 1, que passou novamente a buscar o crescimento no varejo, principalmente no Segmento 5 (clientes com faturamento de até R\$ 600 mil por ano). Um exemplo desse aspecto foi a criação de uma gerência específica de franquia e planejamento para gerir e guiar tal segmento. Além disso, foram desenvolvidos produtos específicos para o segmento, como terminais eletrônicos com aluguel mais baixo e ofertas direcionadas.

Visando alinhar, ainda mais, as estratégias de negócios do Banco 1 e da Credenciadora 1, novas modificações foram realizadas, incluindo a divisão na liderança da empresa. Antes, a Credenciadora 1 possuía um diretor executivo do banco, que também atuava como seu presidente e estava hierarquicamente acima das demais áreas. Devido ao baixo desempenho da área comercial, atualmente o diretor executivo, apesar de ainda ser o presidente, é responsável apenas pelas áreas comerciais da Credenciadora 1. Uma diretoria executiva foi criada voltada apenas para os produtos digitais e as demais áreas de backoffice passaram a responder a outro diretor executivo, conforme apresentado na Figura 7.

Figura 7 - Organograma atual da Credenciadora 1

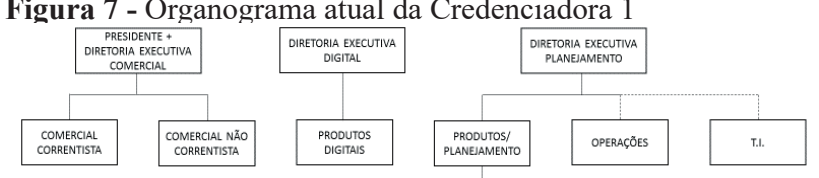

Fonte: Os autores.

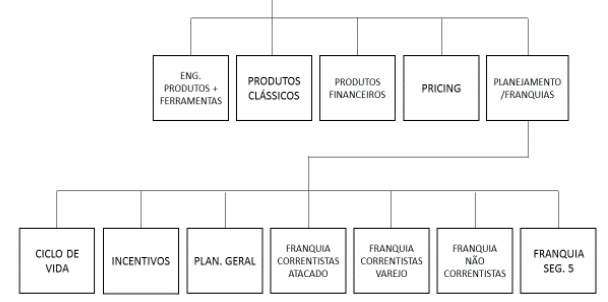

Essa modificação deu-se em função da maior preocupação com a performance da área comercial e com a expectativa de que a área apresente resultados melhores e de forma mais rápida. A criação de uma diretoria executiva responsável pelos produtos digitais da empresa também demonstra que este é um de seus eixos principais de atuação. O grande desafio dessa área é o de aumentar os resultados em vendas online e do uso da carteira digital da Credenciadora 1, produto lançado recentemente.

\section{Conclusão}

O presente estudo teve como objetivo explorar o processo de aquisição de uma empresa do mercado de pagamentos brasileiro, investigando as principais mudanças e impactos na estratégia e na estrutura organizacional e a percepção e a adaptação dos funcionários aos novos elementos culturais desta empresa decorrentes de tal processo.

Fatores como a regulamentação do mercado - que retirou a credenciadora de uma situação confortável de duopólio para um cenário extremamente competitivo - e a própria aquisição da empresa pelo Banco 1 foram determinantes para mudanças em sua estratégia de negócios que afetaram sobremaneira sua estrutura e sua cultura organizacional.

Evidenciou-se que elementos principais da cultura organizacional do Banco 1 foram rapidamente incorporados pela Credenciadora 1. Para isso, o banco delegou cargos de liderança na credenciadora a funcionários que já compreendiam sua cultura e seu modo de atuação e que, conforme relatado pelos entrevistados, foram fundamentais para que o processo de assimilação da cultura do banco fosse mais ágil e eficaz. Outras medidas adotadas foram a incorporação de mecanismos já consolidados no banco, como o modelo de avaliação de desempenho, a digitalização e a cultura de meritocracia. Em relação à estrutura organizacional, seguidas modificações foram realizadas como forma de solucionar problemas existentes na empresa, melhorar os indicadores estratégicos de desempenho e alinhar-se ao modo de funcionamento do banco.

Nesse sentido, a principal contribuição deste estudo é demonstrar que em um contexto no qual as empresas operam sob forte concorrência global, o que exige respostas rápidas às demandas dos clientes e às mudanças no mercado, a interrelação entre estratégia, cultura e estrutura organizacional é dinâmica, adaptativa e mutuamente influente.

Como sugestão para pesquisas futuras, entende-se necessária a realização de novos estudos de caso buscando, em perspectiva comparada, identificar os impactos na estratégia, cultura e estrutura organizacional de empresas que passaram por processos de aquisição ou outros modelos de reestruturação organizacional, tais como fusões, takeovers, terceirizações e off-shorings. Importante, também, uma ampliação do escopo metodológico, com a incorporação de outras técnicas, inclusive quantitativas, para medir os resultados desses processos e sua consequente materialização no campo organizacional.

\section{Referências}

ABECS - Associação Brasileira das Empresas de Cartões de Crédito e Serviços. Mercado de Meios Eletrônicos de 
Pagamento, 2013. Disponível em: <http://www.abecs.org.br/app/ webroot/files/media/7/6/0/b22af92330e3c5e830f69bee3e064. pdf>. Acesso em: 29 ago. 2019.

BACEN - Banco Central do Brasil. Relatório sobre a indústria de cartões de pagamentos: adendo estatístico 2010. 2011. Disponível em: <https://www.bcb.gov.br/htms/spb/Relatorio Cartoes_Adendo_2010.pdf > Acesso em: 29 ago. 2018.

BERGMANN, D.R. et al. Avaliação dos processos de fusões e aquisições no setor bancário brasileiro por meio de estudo de eventos. Rev. Bras. Gestão Negócios, v.17, n.56, p.1105-1115, 2015.

BERNARDO, J.R.R.F.; CAMPOS FILHO, L.A.N. Mapeamento da pesquisa acadêmica em fusões e aquisições. Sistemas \& Gestão, v.5, n.3, p.122-135, 2011.

CALDAS, M.P.; TONELLI, M.J. Casamento, estupro ou dormindo com o inimigo? Interpretando imagens e representações dos sobreviventes de fusões e aquisições. Org. \& Soc., v.9, n.23, p.171-186, 2002.

CAMARGOS, M.A.; CAMARGOS, M.C.S. Mapeamento da produção científica sobre fusões e aquisições na literatura nacional, 1994 a 2014. Rev. Gestão \& Tecnol., v.15, n.3, p.101$137,2015$.

CHANDLER, A.D. Strategy and structure: the history of the american industrial enterprise. Cambridge: Cambridge, 1962.

DAVID, F. R. Strategic management: concepts and cases. New York: Prentice Hall, 2002.

FILIPOVIĆ, D.; PODRUG, N.; KANDŽIJA, T. Successful takeovers and internal organizational variables: Experience from Croatia. Int. J. Organizational Leadership, v.6, p.232-248, 2017.

FREITAS, M. E. Cultura organizacional: grandes temas em debate. Rev. Adm. Empresas, v.31, n.3, p.73-82, 1991.
HOFSTEDE, G. Cultures and organizations: software of the mind. New York: McGraw-Hill, 2010.

MEDEIROS, C.R.O; LOPES, R.C.; POSSAS, M.C. Cultura e mudança organizacional: o processo de incorporação e suas implicações sociais. Rev. Gestão. Org., v.11, n.3, p.559-572, 2013.

MINTZBERG, H.; AHLSTRAND, B.; LAMPEL, J. Safári de estratégias: um roteiro pela selva do planejamento estratégico. Porto Alegre. Bookman, 2010.

PARDINI, D. J.; MACHADO, D. C. C.; OLIVEIRA, G. S. S. Historical Perspective in the Context of Organizational Culture in Acquisition Studies. Revista Gestão \& Conexões, v. 6, n. 2, p. 6-30, 2017.

PESSANHA, G.R.G. et al. Impactos das estratégias de fusão e aquisição na rentabilidade dos bancos adquirentes: uma aplicação dos modelos de intervenção no setor bancário brasileiro. Revista de Administração Mackenzie (Mackenzie Management Review), v. 13, n. 5, 2012.

PIMENTA, D. P.; GARTNER, I. R. Fatores determinantes das fusões e aquisições bancárias no mercado brasileiro. Rev. Finanças Aplic., v.3, p.1-40, 2014.

REGO, A. C. Fusão, aquisição e o impacto na cultura organizacional-estudo de caso Santander e Real. Rev. Adm. Unisal, v.4, n.5, 2014.

SILVA, A.L.; DUARTE, M.F. A interface entre sentimentos e cultura organizacional: evidências de uma operação de aquisição. Gestão Soc., v.6, n.13, p.26-46, 2012.

TORTATO, U.; DEL CORSO, J. Mudança na Configuração Estrutural em Aquisições de Empresa Nacional por Multinacional. Rev. Adm., v.6, n.2, p.66-86, 2008. 